\title{
ADAPTAÇÃO E INTERMIDIALIDADE: REFLEXÕES SOBRE MACBETH, A ÓPERA CORO DE GIUSEPPE VERDI
}

\author{
ADAPTATION AND INTERMEDIALITY: REFLECTIONS ON MACBETH, \\ VERDI'S CHORAL OPERA
}

\author{
Anna Stegh Camati \\ UNIANDRADE, Curitiba, Paraná, Brasil \\ ascamati@gmail.com
}

\begin{abstract}
Resumo: A ópera, uma forma de teatro musical, é a arte da adaptação por excelência, constituída pela integração e fusão de múltiplas linguagens artísticas. A presente pesquisa objetiva refletir sobre a ópera Macbeth (1847-1865), de Giuseppe Verdi (1813-1901), baseada no texto homônimo (1605) de Shakespeare (1564-1616), à luz de perspectivas teóricas de Linda e Michael Hutcheon (2011; 2017), Lars Elleström (2017); Hans Ulrich Gumbrecht (2011) e outras. Assim como Richard Wagner (1813-1883), Verdi foi um dos primeiros compositores preocupados com os aspectos dramáticos e cênicos de suas óperas. São atribuídas a ele diversas inovações, entre elas a formulação do manual da mise-en-scène e a criação de ambiência ou Stimmung. Em relação à ópera Macbeth, Verdi destacou o papel das bruxas por meio de um coro feminino de trinta vozes por acreditar que elas são o elemento propulsor do drama. No início do quarto ato, introduziu o coro dos exilados escoceses com o intuito de expressar seus próprios anseios de liberdade em relação ao movimento de unificação da Itália. As diversas especificidades da ópera verdiana serão discutidas enquanto modelo textual (libreto), composição musical (partitura) e performance dramática (concretização cênica).
\end{abstract}

Palavras-chave: Giuseppe Verdi; Macbeth; Ópera Coro; Adaptação; Intermidialidade

\begin{abstract}
Opera, a form of musical theatre, is the art of adaptation par excellence, consisting of the integration and fusion of multiple artistic languages. This research paper aims at reflecting on the opera Macbeth (1947/ 1865), by Giuseppe Verdi (1813-1901), based on the homonymous text (1605) by Shakespeare (1564-1616), in the light of theoretical perspectives by Linda and Michael Hutcheon (2011; 2017), Lars Elleström (2017); Hans Ulrich Gumbrecht (2011) and others. Like Richard Wagner (1813-1883), Verdi was one of the first composers concerned with the dramatic and scenic aspects of his operas. Several innovations are attributed to him, including the formulation of mise-en-scène manual and the creation of ambience or Stimmung. As concerns the opera Macbeth, Verdi highlighted the role of the witches through a female chorus of thirty voices for believing they are the driving force of the drama. At the beginning of act four, he introduced a chorus of Scottish exiles to express his own longings for freedom regarding the movement for the unification of Italy. The various specificities of the Verdian opera will be discussed as textual model (libretto), musical composition (score) and dramatic performance (scenic concretization).
\end{abstract}

Keywords: Giuseppe Verdi; Macbeth; Choral Opera; Adaptation; Intermediality 
Desde a sua incepção na Itália do século XVI, a ópera é uma forma de arte plurimidiática, constituída pela integração e fusão de diversas linguagens artísticas oriundas da literatura, música, teatro, dança e artes plásticas. Como outras formas de arte, sofreu variações através dos tempos, sendo que o repertório romântico tornou-se a modalidade dominante no século XIX.

A ópera romântica privilegiou peças de teatro e romances trágicos como textos-fonte e, consequentemente, a obra de Shakespeare atraiu a atenção de grandes compositores. Diversos textos do dramaturgo inglês foram utilizados para a criação de óperas famosas, entre elas Otello (1816), de Gioachino Rossini (1792-1868); Macbeth (1847-1865), Othello (1887) e Falstaff (1893), de Giuseppe Verdi (1813-1901); Béatrice et Bénédict (1862), de Hector Berlioz (1803-1869); e Roméo et Juliette (1867), de Charles Gounod (1818-1893).

A abertura, maleabilidade e plasticidade quase infinita dos textos de Shakespeare proporciona inúmeras possibilidades criativas ao artista no percurso intermidiático através do tempo e espaço. Quando transformados em roteiros cênicos, fílmicos ou libretos de ópera, o resultado é sempre um novo texto, com diversos graus de aproximação ou distanciamento em relação ao texto-fonte. Essa passagem pressupõe uma série de transformações, visto que os diversos suportes são regidos por diferentes signos, códigos e convenções. Hoje temos consciência que a identidade entre o texto de origem e o de chegada, seja ele cênico, fílmico ou operístico é impossível e mesmo indesejável. Como ensina Júlio Plaza "mesmo o processo pretendidamente mimético caracteriza-se pelo fato de algo tentar fazer-se igual a outro, mostrando-se como não igual. [...] Representar a coisa 'tal como ela é' é mimese mediada pelo código. Quer dizer, a similaridade já contém seu tom diferenciador" (PLAZA, 2003, p. $33)$.

Existem duas versões diferentes da ópera coro Macbeth, a da estreia no Teatro della Pergola (Florença, 1847), com libreto de Francesco Maria Piave (1810-1876) elaborado a partir da versão em prosa do compositor, e a versão revista e ampliada no Théâtre Lyrique (Paris, 1865), com diversas adaptações e adições ao libreto "original" por parte de Verdi e partes reescritas por Andrea Maffei (1798-1885).

\section{Perspectivas teóricas}

A primeira parte do título do presente ensaio remete ao artigo "Adaptation and Intermediality" (2017), no qual Lars Elleström postula haver uma relação de subordinação entre adaptação e intermidialidade. Com o intuito de situar a noção de adaptação dentro do campo acadêmico mais amplo da intermidialidade, o crítico sueco apresenta dez pressupostos teóricos que versam sobre aspectos negligenciados em transações e trânsitos intermidiáticos. Para fundamentar sua tese, apresenta dois argumentos principais. No primeiro, com base em uma perspectiva sincrônica, sustenta que todas as mídias são intermidiáticas e multimodais, compostas de elementos que só serão inteiramente compreendidos em relação a outras mídias com as quais compartilham traços básicos. No segundo, concebido a partir de uma ótica diacrônica, afirma que os elementos compositivos das mídias em geral são transmidiáticos e, portanto, podem ser transferidos para diferentes tipos e produtos de mídia. Nesse sentido, a adaptação pode ser vista como um fenômeno específico de transformação de mídias ou "transmidiação: uma mídia representa novamente, mas de maneira diferente, algumas características que já foram representadas em outras configurações midiáticas" (ELLESTRÖM, 2017, p. 512) ${ }^{1}$.

No artigo "Opera and Adaptation" (2017), Linda e Michael Hutcheon argumentam que a ópera, desde os seus primórdios, evidenciou seu pendor pela adaptação. Por ser uma

\footnotetext{
${ }^{1}$ Todas as traduções de citações em língua estrangeira, cujos tradutores não constam da bibliografia, são minhas.
} 
prática notoriamente dispendiosa, os compositores geralmente recorrem à adaptação de fontes confiáveis e bem-sucedidas financeiramente a fim de evitar problemas de ordem econômica, privilegiando "não o novo ou o 'original', porém o testado e o experimentado" (HUTCHEON; HUTCHEON, 2017, p. 305). Afirmam, ainda, que todos os envolvidos no processo de criação e produção de uma ópera são adaptadores: o libretista adapta um texto fonte para escrever o libreto, o compositor adapta o libreto ao criar a partitura, e o régisseur adapta a ambos, o libreto e a partitura, na transposição dos textos verbal e musical para a cena.

Esta proposição de três etapas distintas para a análise concreta de óperas encontra respaldo, em diversos aspectos, nos pressupostos teóricos apresentados por Elleström no artigo mencionado, principalmente naqueles que envolvem questões a respeito de fontes intermediárias do processo de adaptação, denominadas por ele de assisting media (mídias auxiliares criadas especificamente com o objetivo de serem transmediadas), tais como libretos, partituras musicais, roteiros cênicos e fílmicos, promptbooks, desenhos preliminares, maquetes, etc., as quais geralmente são pouco exploradas ou mesmo ignoradas em análises que se debruçam sobre diálogos entre mídias diversas.

A partir das colocações de Elleström sobre as mídias auxiliares e do modelo de análise tripartido elaborado pelos críticos canadenses, objetiva-se desenvolver uma reflexão a respeito de alguns aspectos que nortearam a criação da ópera Macbeth (1847-1865), de Giuseppe Verdi (1813-1901), inspirada no texto homômimo (1605) de Shakespeare (15641616). A ópera coro será discutida enquanto modelo textual (libreto), composição musical (partitura) e performance dramática (encenação).

\section{O texto shakespeariano adaptado em forma de libreto}

Assim como Richard Wagner, Verdi foi um dos primeiros compositores a pensar a ópera como Gesamtkunstwerk, ou obra de arte total, e a exercer controle absoluto em todas as etapas de criação e produção: ele não se limitava a compor a música vocal e instrumental, mas concebia e estruturava em linhas gerais o libreto, e atuava como regente (maestro), régisseur (diretor de cena) e ensaiador. Sabe-se que, para produzir o texto do libreto, o compositor utilizou não somente várias traduções italianas da peça de Shakespeare, mas também descrições cênicas da adaptação semi-operística Macbeth (1664), de William Davenant (16061668), na qual as bruxas cantam e dançam e o papel de Lady Macbeth é expandido, além de considerações críticas de August Wilhelm Schlegel, cuja visão sobre a peça, baseada nos ditames do Romantismo literário do século XIX, iam de encontro com as suas próprias sensibilidades estéticas.

Em carta para Tito Ricordi, de 11 de abril de 1857, Verdi revelou que em 1847, após ter escrito o roteiro operístico completo da ópera Macbeth em prosa, com divisões em atos, cenas e números musicais, passou o material textual para o libretista Francesco Maria Piave para que transformasse a prosa em verso. Em seguida, confessou não ter ficado inteiramente satisfeito com a versificação de Piave e, por conta disso, para a versão parisiense de 1865 , pediu para Andrea Maffei reescrever (segundo ele, com o consentimento de Piave) partes do libreto "original", tais como as intervenções córicas das bruxas no terceiro ato e a cena do sonambulismo de Lady Macbeth. Além disso, introduziu, na abertura do quarto ato, o coro dos refugiados escoceses e modificou o final como veremos mais adiante (ROSEN; PORTER, 1984). Este depoimento indica que Piave, na realidade, simplesmente desempenhava o papel de amanuense literário de Verdi, no sentido técnico e não criativo em relação à ópera Macbeth.

Linda Hutcheon nos alerta que os espectadores geralmente não se dão conta do papel extremamente difícil exercido pelo libretista, porque "a adaptação como adaptação envolve, 
para seu público conhecedor, uma duplicação interpretativa, um movimento conceitual para frente e para trás entre a obra que conhecemos e aquela que estamos experienciando" (HUTCHEON, 2011, p. 67). Em face dessa duplicidade de visão, que envolve a memória e a experiência do espectador no momento da recepção, o libretista (nesse caso, um papel também assumido pelo compositor) geralmente é considerado culpado da simplificação do texto verbal adaptado, por realizar grandes cortes que, segundo a opinião de parte da audiência com conhecimento do texto fonte, implicam em perda de qualidade. No entanto, como aponta Hutcheon (2011, p. 67), a compressão é estritamente necessária na arte operística, tendo em vista que leva "muito mais tempo para cantar do que para recitar uma linha ou simplemente lê-la".

No entanto, a incompletude do libreto, é compensada pela criação musical. Nesse sentido, Verdi mostrou consciência da necessidade de adaptação do texto fonte às convenções operísticas, pois uma redução drástica do texto de Shakespeare foi realizada para atender as exigências do novo gênero: redução de personagens, ênfase na emoção ao invés de refexões críticas, cortes de partes de cenas ou cenas inteiras (a cena do porteiro, por exemplo), deslocamentos, paráfrases e encurtamentos de falas, transformação de falas em intervenções córicas, etc.

Desde o início, Verdi advertiu seu libretista Francesco Maria Piave sobre a necessidade não somente de cortar grande parte do texto de Shakespeare, mas de reduzir drásticamente o número de personagens, concentrando a ação em torno de Macbeth, Lady Macbeth e as bruxas. Em carta escrita em 8 de fevereiro de 1865, para Léon Escudier (18211881), jornalista, crítico e editor de sua obra na França, o compositor recomendou:

Tenha em mente que os papéis principais desta ópera são, e só podem ser, três: Macbeth, Lady Macbeth e o coro das bruxas. As bruxas dominam o drama; é nelas que tudo tem origem - grosseiras e mexeriqueiras no Ato I, exaltadas e proféticas no Ato III. Elas compõe uma personagem autêntica e de grande importância. (VERDI Apud WILLS, 2011, p. 39)

Assim, Verdi deu enorme destaque ao papel das bruxas, através de um coro feminino de trinta vozes (três grupos de dez mulheres) que atuam como personagens, por acreditar que elas são o elemento chave do drama, pois despertam os desejos inconscientes de Macbeth, desencadeando a volta do estranho familiar há muito tempo esquecido, ou seja, o que as bruxas dizem já foi desejado e recalcado por Macbeth ${ }^{2}$. A consciência do infamiliar (das Unheimliche) (FREUD, 2019) surge da confrontação com as bruxas, cujas palavras engendram o retorno de seus pensamentos sanguinários para tornar-se rei, e esse mal-estar experimentado desestabiliza as bases da identidade de Macbeth. A partir daí ele se torna outro.

O papel de Lady Macbeth é ampliado e seu lado cruel e sanguinário é sublinhado: enquanto em Shakespeare, depois da coroação ela não participa da caminhada sangrenta de Macbeth, cujo intuito é manter-se no poder, em Verdi, ela é cúmplice de todas as atrocidades cometidas por ele. Por outro lado, de acordo com Penny Gay (2016), ela aparece extremamente fragilizada na cena do sonambulismo, uma parte da ópera quase idêntica ao texto escrito por Shakespeare.

\footnotetext{
2 Trata-se de um processo psicológico teorizado por Sigmund Freud, no ensaio Das Unheimliche, publicado em 1919, descrito como uma inquietação que perturba por se tratar da volta do estranho familiar há muito tempo esquecido. Esse fenômeno é mais evidente no texto de Shakespeare, específicamente no primeiro solilóquio de Macbeth e em uma de suas falas subsequentes, quando o protagonista, absorto em seus pensamentos é interpelado por Banquo, ao qual responde: "Perdão; a minha mente se ocupava/Com coisas esquecidas" (3.2.145-146). Na ópera, esse solilóquio é encurtado e modificado, mas há uma referência breve que alude à consciência do infamilar ou sinistro discutido por Freud (2019), quando Macbeth exclama: "Pensamento sanguinário, de onde surgiste?”.
} 
Com relação ao tempo, as duas obras, o texto dramático e o texto operístico, foram criados em diferentes contextos culturais e de enunciação. Como ressalta Patrice Pavis (2008, p. 123-154), na passagem de uma mídia para a outra, um aspecto importante a ser considerado é o diálogo de mão dupla no cruzamento de situações de enunciação e/ou culturas. Nesse sentido, no texto operístico, o núcleo da narrativa dramática de Macbeth foi transposto para o imaginário cultural do século XIX, no qual houve grandes mudanças no tocante às crenças em bruxarias.

No século XVII, durante o reinado de Jaime I houve um tempo de caça às bruxas (julgamentos, torturas e execuções públicas) após o Complô da Pólvora, portanto, a bruxaria era considerada uma questão teológica e política. Por outro lado, em meados do século XIX, novas óticas prevaleceram em relação à bruxaria decorrentes do ceticismo em relação à existência de feiticeiras. No entanto, em virtude da difusão da estética gótica e romântica, o fascínio pelo diabolismo permaneceu e, apesar das falas das bruxas serem semelhantes em ambas as mídias, houve um redirecionamente de sentido em função da mudança temporal e do contexto cultural.

Sendo assim, apesar da enorme compressão necessária para viabilizar o discurso operístico, foi mantido e, muitas vezes, expandido, todo o material textual shakespeariano com elementos góticos, a saber todas as cenas do primeiro e segundo encontro com as bruxas, a cena do punhal imaginário e a cena do banquete na qual aparece o fantasma de Banquo.

A mudança de contexto cultural também permitiu a inserção de alusões políticas e morais relativas época em que o texto operístico foi levado à cena. Nesse sentido, Verdi, um fervoroso militante político do Risorgimento, o movimento de unificação e independência da Itália, modifica a primeira versão de Macbeth, de 1847, e introduz, na abertura do quarto ato da versão parisiense de 1865 , o coro dos refugiados escoceses que entoam sua insatisfação em relação ao status-quo cantando "Patria oppressa" ("Pátria oprimida"). O texto dessa intervenção córica é uma compilação e modificação de falas, principalmente do quarto ato do texto shakespeariano, no qual o príncipe Malcolm e o representante da nobreza Macduff engendram um plano para derrotar o regime de tirania de Macbeth. Nesse canto coral há também uma mudança de ênfase em relação ao texto-fonte: a preocupação com a libertação dos oprimidos e o combate à tirania é colocada na boca do povo ao invés de ser discutida por nobres.

O final da versão parisiense também se afasta totalmente do texto de Shakespeare: ao invés de manter a estrutura circular presente no texto de Shakespeare, que começa com Duncan distribuindo títulos nobiliárquicos após a batalha e termina com Malcolm sendo coroado e reeditando essa tradição, sugerindo que um novo ciclo de violência está prestes a começar, a ópera termina com o coro dos refugiados celebrando a vitória sobre a tirania.

\section{Do libreto à partitura: a linguagem musical da ópera criada por Verdi}

A segunda etapa do processo criativo de uma ópera consiste na tradução do material textual em linguagem musical, ou seja, a narrativa verbal do libreto é transformada pelos compositores em música vocal - árias, duetos e coros - música instrumental e recitativos. No entanto, não se trata de música "absoluta"; a composição operística é sempre música adaptada ao texto. Nesse sentido,

[...] sempre haverá uma dimensão extra-musical porque ela é escrita para dar voz, literalmente, a um texto dramático em palavras. Assim, há uma linha vocal e outra de música orquestral, e a relação entre essas duas partes pode ser de duplicação, ênfase, ironia ou contradição. As passagens orquestrais que não se relacionam às palavras também apresentam associações extra-musicais a partir do seu contexto dentro da ópera, mas, além disso, elas também acumulam significado à medida em 
que a ópera se desenrola. A forma e a função de todas essas modalidades de música operística é variável, dependendo de tempos e contextos históricos específicos. (HUTCHEON; HUTCHEON, 2017, p. 312)

Em Macbeth, Verdi empreende uma reinterpretação da dimensão sonora da ópera clássica romântica, optando por inúmeras inovações e avanços formais, como a declamação expressiva e a orquestração não convencional. Apesar de que ainda usa diversas convenções da ópera romântica e faz referências a Rossini, sua admiração pelo texto de Shakespeare foi responsável pela inspiração para a criação de música vocal e instrumental diferenciada de enorme força e sutileza.

O compositor privilegiou a vetorização musical: o canto coral das bruxas constitui o núcleo propulsor que governa a narrativa operística pela sua enorme força e expressividade. $\mathrm{O}$ compositor consegue recriar a atmosfera ou Stimmung sinistra veiculada pela poesia encantatória e retórica de Shakespeare por meio de música vocal e instrumental, tecendo nuanças musicais inusitadas e diferenciadas que propiciam um acúmulo de apelos sensoriais, além dos cinco sentidos, conduzindo o espectador a um envolvimento visceral e orgânico e acionando os fluxos energéticos que causam espanto e perturbação. Assim, segundo Hans Ulrich Gumbrecht (2014), ler o texto de Shakespeare com a atenção voltada para a ambiência ou Stimmung, significa prestar atenção à dimensão textual das formas que envolvem nossos corpos enquanto realidade física. Nesse sentido, a música de Verdi investe as palavras de uma existência palpável e corpórea, dando a elas uma nova materialidade, com energia e dimensão diferentes.

Verdi revolucionou as estruturas composicionais da ópera italiana, flexibilizando as antigas formas fixas de composição em função de uma maior veracidade teatral. "A tradicional scena tripartite, feita de recitativo, ária e cabaleta vai sendo gradualmente abandonada em troca de formas mais livres. [...] Também as vozes, no teatro verdiano, terão de se adaptar aos personagens, para expressar melhor o drama segundo a concepção particular do autor" (CASOY, 2006, p. 46).

\section{Verdi, o compositor-encenador: do libreto e partitura à concretização cênica}

A integração de palavra e música na ópera encenada é um discurso sincrético, uma vez que se configura a partir "dois ou mais sistemas de signos e/ou mídias de uma forma tal que os aspectos visuais e/ou musicais, verbais, cinéticos e performativos de seus signos se tornam inseparáveis e indissociáveis" (CLÜVER, 2006, p. 20). De acordo com essa linha de raciocínio, Freda Chapple (2006) postula que o discurso operístico, ou seja, as palavras cantadas e mediadas pela voz do performer no momento da recepção da ópera encenada, pode ser visto não como uma justaposição de música e palavra, mas como a fusão de ambas em um novo idioma. Em sua análise, a autora utiliza o epíteto de "performer intermidiático" para o ator-cantor de ópera por emprestar sua voz para cantar a poesia musicada: ele é um mediador que funde o texto escrito ou libreto com a partitura musical, tornando-se, portanto, o principal veículo de enunciação do discurso sincrético do espetáculo operístico, uma forma intermidiática por excelência.

$\mathrm{Na}$ montagem de uma ópera, além do discurso sincrético, constituído pela fusão de palavras e música, outras especificidades do teatro contribuem para a composição da cena, como o trabalho de expressão facial e corporal dos atores, o cenário, a iluminação e outros recursos audiovisuais que interferem na gênese da criação artística. Trata-se de um processo transformacional intermidiático, no qual os componentes visuais, auditivos, gestuais e corporais, mencionados acima, são convertidos em situações materiais concretas constitutivas 
da narrativa operística. Cumpre ressaltar, ainda, que as convicções individuais sobre a criação do espetáculo operístico variam de uma montagem para outra, visto que todo régisseur é, antes de tudo, um leitor que irá imprimir sua ótica particular ao espetáculo que será levado ao palco (HUTCHEON; HUTCHEON, 2017).

Enquanto a escritura do libreto e a composição da partitura geralmente são criações individuais, a concretização cênica de uma ópera é uma arte coletiva. No entanto, Verdi dispensava o processo de criação coletiva em larga escala e fazia questão de se engajar sozinho nas tarefas da concepção e produção do espetáculo operístico. Preocupado com as dimensões cênicas de suas óperas, uma das inovações atribuídas a Verdi foi a adaptação do livret de mise-en-scène parisiense, no manual, descritivo e detalhado, intitulado disposizione scenica, no qual indicações precisas sobre todos os aspectos da concretização cênica eram especificados. Esses manuais baseados em performances de suas óperas, incluiam

[...] descrições de cenários, figurinos e acessórios, rubricas detalhadas sobre a expressão facial e corporal (muitas vezes acrescidas de explicações sobre a motivação dos gestos indicados), detalhes sobre como organizar as sucessão de ações para facultar a rápida mudança de cenas, dicas para a iluminação, croquis de desenhos que mostram a movimentação cênica durante o desenrolar de cada cena [...]. (SADIE, 1980, p. 647)

Os aspectos verbais, musicais e visuais eram claramente definidos nesses manuais, muitas vezes com explicações sobre as personalidades e timbres de voz dos atores-cantores. Verdi considerava que a capacidade de declamar palavras de maneira vívida e uma presença cênica energética eram qualidades mais importantes em um cantor do que uma técnica vocal apurada. Nesse sentido, o compositor compunha sua música com cantores específicos em mente. Com relação à opera Macbeth, ansiava livrar-se das amarras do bel canto. Almejava contratar cantores de voz e aparência fora do padrão. Assim, rejeitou Eugenia Tadolini, uma prima donna de extraordinária beleza e dominio vocal perfeito para o papel de Lady Macbeth, e optou por Marianna Barbieri-Nini que não se enquadrava em padrões de beleza da época, mas cuja voz alcançava acordes diabólicos os quais acreditava serem próprios para a caracterização da personagem.

As memórias de Mariana Barbieri-Nini, a primeira Lady Macbeth, sobre o longo processo de ensaios para ajustar o seu papel ao entendimento que Verdi nutria a respeito da caracterização da personagem, mostram a preocupação do compositor com a expressão facial e corporal. Em seu relato, ela comenta:

Eu me lembro que para Verdi havia dois pontos culminantes na ópera: a cena do sonambulismo e o meu dueto com o barítono. Vocês não vão acreditar, mas a cena do sonambulismo me custou três meses de estudo: por três meses, da manhã à noite, eu tentava imitar aqueles que falam durante o sono, enunciando palavras (como Verdi me dizia) quase sem mover os lábios, e permanecendo com o restante da face imóvel, inclusive os olhos. Era o bastante para enlouquecer uma pessoa. [...] Em relação ao dueto, vocês podem achar que estou exagerando, mas ele foi ensaiado mais do que cento e cinquenta vezes para que se aproximasse mais da fala do que do canto...(ROSEN; PORTER, 1984, p. 52-53)

Verdi impôs a mesma regra para Felice Varesi, o barítono que deveria encarnar o papel do protagonista:

Varesi é o único artista italiano hoje capaz de asumir o papel que eu tenho em mente, por seu estilo vocal e sua sensibilidade - e também pela sua aparência. Todos os outros artistas, mesmo os melhores que ele, não chegariam à altura do papel que criei - sem desmerecer Ferri, o qual têm melhor aparência, voz mais bonita e, 
porque não dizer, é um cantor melhor -, mas no papel mencionado ele certamente não teria o mesmo rendimento de Varesi. (VERDI Apud WILLS, 2011, p. 32)

\section{Considerações finais}

A apropriação e adaptação das obras de Shakespeare em outras mídias é contínua, não como uma manifestação de nostalgia de uma época, mas como resposta às questões de tempos contemporâneos (SANDERS, 2007). A ópera Macbeth, de Verdi, é uma obra-prima do gênero que mantém o mesmo sabor de novidade e criatividade desde a época de sua incepção, e prossegue como inspiração e modelo de diferentes produções cênicas de óperas, teatro operístico filmado e filmes operísticos ao redor do mundo.

Apesar de acreditar que seguia Shakespeare de perto na transposição (ou transmidiação) do material textual para a mídia operística, na realidade Verdi realiza uma apropriação da narrativa dramática de Macbeth, e altera completamente diversos elementos narrativos, entre eles a caracterização, a causalidade, o tempo e o espaço. Trata-se de uma transcriação, a qual constitui-se como expressão original do gênio artístico do compositor que optou por interfaces e cruzamentos complexos e arrojados: os protocolos tradicionais da ópera italiana foram subvertidos por meio da mistura e fusão de múltiplas linguagens, resultando em uma síntese criativa que enriqueceu e revitalizou não somente a ópera romântica do século XIX, mas também a dramaturgia de Shakespeare.

\section{Referências}

Casoy, Sergio. Óperas e outros cantares. São Paulo: Perspectiva 2006.

Chapple, Freda. "Digital Opera: Intermediality, Remediation and Education". In: Chapple, Freda; Kattenbelt, Chiel (Eds). Intermediality in Theatre and Performance. Amsterdam and New York: Rodopi, 2006, p. 81-100.

Clüver, C. Inter textus/Inter artes/ Inter media. Tradução de Elcio Loureiro Cornelsen. Aletria: Revista de Estudos de Literatura - Intermidialidade, [s.l]. v. 14, jul./dez. 2006, p. 11-41.

Elleström, Lars. "Adaptation and Intermediality". In: In: Leitch, T. (Ed.). The Oxford Handbook of Adaptation Studies. Oxford and New York: Oxford University Press, 2017, p. $509-526$.

Gay, Penny. "Shakespeare and Opera". In: Edmondson, Paul; Holbrook, Peter. Shakespeare's Creative Legacies: Artists, Writers, Performers, Readers. London and New York: Bloomsbury, 2016, p. 79-91.

Freud, Sigmund. $O$ infamiliar (Das Unheimliche). Tradução de Ernani Chaves e Pedro Heliodoro Tavares. Belo Horizonte: Editora Autêntica, 2019.

Gumbrecht, Hans Ulrich. "Em busca de Stimmung: como pensar hoje na realidade da literatura". In: Gumbrecht, Hans Ulrich. Atmosfera, ambiência, Stimmung. Rio de Janeiro: Contraponto, Editora PUCRio, 2014, p. 9-33.

Hutcheon, Linda. Uma teoria da adaptação. Tradução de André Cechinel. Florianópolis: Editora da UFSC, 2011. 
Hutcheon, Linda; Hutcheon, Michael. "Adaptation and Opera". In: Leitch, T. (Ed.). The Oxford Handbook of Adaptation Studies. Oxford and New York: Oxford University Press, 2017, p. 305-323.

Plaza, Júlio. Tradução intersemiótica. São Paulo: Perspectiva, 2003.

Rosen, David; Porter, Andrew (Eds). Verdi's Macbeth: a Sourcebook. New York: W. W. Norton and Company, 1984.

Sadie, Stanley (Ed.). The New Grove Disctionary of Music and Musicians. London: Macmillan, 1980.

Sanders, Julie. Shakespeare and Music: Afterlives and Borrowings. Cambridge UK and Malden USA: Polity Press, 2007.

Shakespeare, William. Macbeth. Trad. Barbara Heliodora. Rio de Janeiro: Lacerda, 2004.

Verdi. Giuseppe. Libretto in Italian with Translation into English. Disponível em: http://www.operafolio.com/libretto.asp?n=Macbeth\&translation=UK. Acesso em: 17.05.2019.

Wills, Garry. Verdi's Shakespeare: Man of the Theater. New York: Penguin, 2011.

Recebido em: 27 de agosto de 2019

Aceito em: 29 de novembro de 2019

Publicado em: Dezembro de 2019 